\title{
Madre y mujer gitana. Joaquina la gitana de Joaquín Sorolla
}

\section{Mother and roma woman. Joaquina la gitana, Joaquin Sorolla Mãe e mulher cigana. Joaquina la gitana, Joaquin Sorolla}

María Dolores Gil Estevan ${ }^{1}$ Maria del Carmen Solano Ruiz ${ }^{2}$

${ }^{1}$ Enfermera de Interrelación Departamento de Salud de Elda. Estudiante de Doctorado (Cultura de los Cuidados)

${ }^{2}$ Profesora Titular Facultad de Ciencias de la Salud de la Universidad de Alicante

Cómo citar este artículo en edición digital: Gil Estevan, Ma.D; y Solano Ruiz, Ma.C. (2014) Madre y mujer gitana. Joaquina la gitana de Joaquín. Cultura de los Cuidados. (Edición digital) 18, 40. Disponible en: http://dx.doi.org/10.7184/cuid.2014.40.15

Correspondencia: Departamento de enfermería. Universidad de Alicante. 03080-Alicante. Correo electrónico: lola.gilesteban@gmail.com

Recibido: 13/05/2014; Aceptado: 11/10/2014

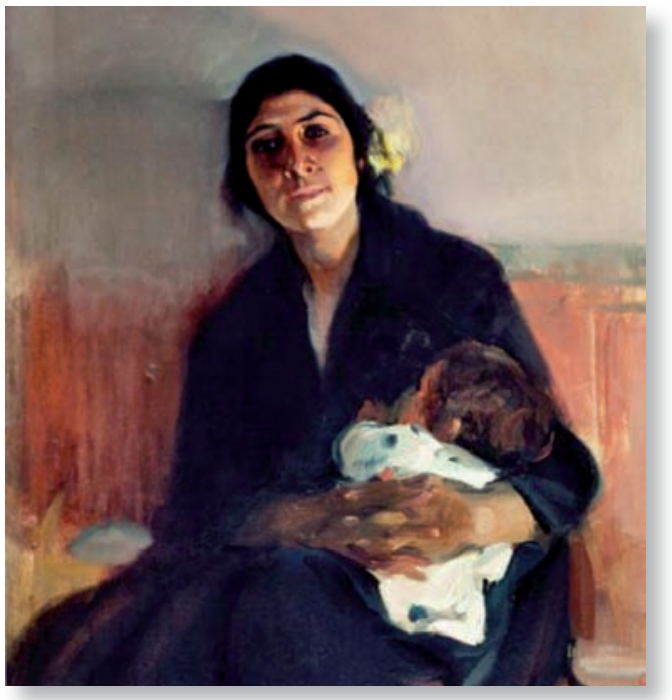

Joaquina la gitana. Joaquín Sorolla. Museo Sorolla, Madrid (http://museosorolla.mcu.es/historia.htm)

\section{ABSTRACT}

The iconography aims describing images. It allows us to understand the images on their semantic aspects, as is knowledge of the methods and analysis, and in order to unlock the messages hidden behind them, being a fundamental knowledge of the culture element.

By analyzing the work of Joaquín Sorolla, Joaquina la gitana, we intend to make an approach to the reality of Roma women within their social context, following the three levels of significance of Erwin Panofsky.

We thus find two personalities of the same woman. We are introduced to a woman dressed in black, one rooted in the traditions woman in the left hand. Is the "woman of respect" that meets the standards of the Roma people. And in another quite different style, is reflected the maternal aspect of the Roma, portrayed bright despite being a shadowy figure, with her child who appears to be breastfeeding.

Through the analysis of this work, we have come a little closer to the reality of Roma women, and understand their experiences within the cultural environment of the Roma people.

Keywords: culture, gender, iconography, roma woman.

\section{RESUMO}

A iconografia tem como objetivo descrever as imagens. Ela nos permite compreender as imagens em seus aspectos semânticos, como é do conhecimento dos métodos e análise e, a fim de desbloquear as mensagens escondidas por trás deles, sendo um conhecimento fundamental do elemento de cultura.

Ao analisar a obra de Joaquín Sorolla, Joaquina Gypsy, pretendemos fazer uma aborda- 
gem à realidade das mulheres de etnia cigana dentro de seu contexto social, seguindo os três níveis de significância de Erwin Panofsky.

Temos, assim, encontrar duas personalidades de uma mesma mulher. Somos apresentados a uma mulher vestida de preto, um enraizado em tradições a mulher na mão esquerda. É a "mulher de respeito" que atenda aos padrões do povo cigano. E em outro estilo bem diferente, reflete o aspecto maternal da Roma, retratado brilhante, apesar de ser uma figura sombria, com seu filho, que parece estar a amamentar.

Através da análise deste trabalho, chegamos um pouco mais perto da realidade das mulheres ciganas, e compreender as suas experiências dentro do ambiente cultural do povo cigano.

\section{RESUMEN}

La iconografía tiene como objetivo la descripción de las imágenes. Nos permite conocer las imágenes en sus aspectos semánticos, ya que consiste en el conocimiento y análisis de las formas, y en el propósito de desvelar los mensajes que tras ellas se ocultan, siendo un elemento fundamental para el conocimiento de la cultura.

Mediante el análisis de la obra de Joaquín Sorolla, Joaquina la gitana, pretendemos realizar una aproximación a la realidad de las mujeres gitanas dentro de su contexto social, siguiendo los tres niveles de significación de Erwin Panofsky.

Encontramos así dos personalidades de la misma mujer. En la parte izquierda, se nos presenta a una mujer vestida de negro, una mujer arraigada a las tradiciones. Es la "mujer de respeto" que cumple con las normas del pueblo gitano. Y en otro estilo bien distinto, aparece reflejado el aspecto maternal de la gitana, retratada con mucha luz a pesar de ser una figura muy oscura, con su hijo en brazos al que parece estar dando el pecho.

A través del análisis de esta obra, nos hemos acercado un poco más a la realidad de la mujer gitana, y comprender sus vivencias, dentro del entorno cultural del pueblo gitano.

Palabras clave: cultura, género, iconografía, mujer gitana.

\section{INTRODUCCIÓN}

En palabras de Erwin Panofsky: una obra de arte es un producto de la mente que culturalmente cristalizada, da lugar a la forma. (Panofsky, 1955 en Rodríguez, 2005)

La iconografía tiene como objetivo de estudio la descripción de las imágenes, pero no sólo eso, ya que éstas son transmisoras de mensajes, y su lectura, en muchas ocasiones, esconde significados cargados de connotaciones culturales e intelectuales. La iconografía nos permite conocer no sólo las imágenes en cuanto a su forma y estética, sino también en sus aspectos semánticos, ya que consiste tanto en el conocimiento y análisis de las formas, como en el propósito de desvelar los mensajes que tras ellas se ocultan (Rodríguez, 2005).

De ahí la importancia de la iconografía como elemento fundamental para el conocimiento de la cultura, ya que como muy bien dice en sus estudios Erwin Panofsky, cada obra de arte debe ser entendida y analizada como una expresión cultural mucho más compleja que un combinado de técnicas, y colores, en la que se investiguen sus formas y significados, conectándolos con la filosofía, la sociología, la música, la religión ..., e intentando reconstruir los fundamentos culturales en los que ha sido elaborada. 


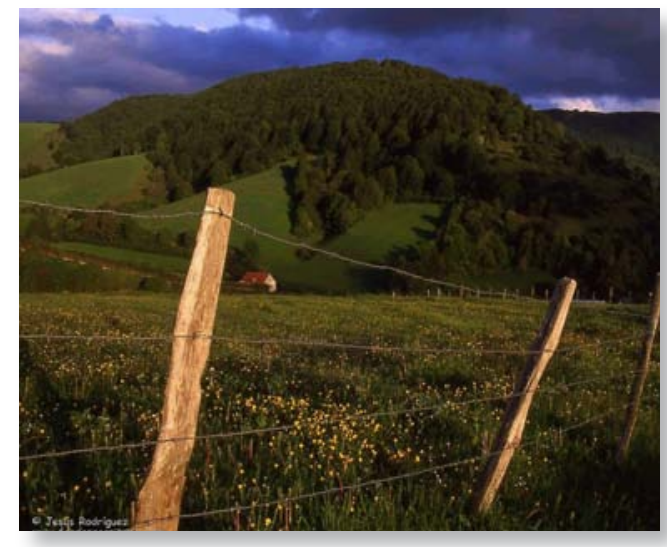

\section{OBJETIVO}

Realizar una aproximación a la realidad de las mujeres gitanas dentro de su contexto social, siguiendo los tres niveles de significación de Erwin Panofsky (Amezcua, 2012 y Rodríguez, 2005) analizando la obra de Joaquín Sorolla titulada, "Joaquina la gitana".

\section{DESARROLLO}

Para llevar a cabo el análisis de este cuadro es importante conocer la biografía de su autor, con el fin de poder identificar y contextualizar la etapa y las influencias bajo las que fue concebida esta obra, ya que el artista que piensa en un determinado tiempo y lugar, refleja en su obra la idea o espíritu de su época. Las obras de arte, representan por tanto, a los pueblos. (Medina, Sánchez, Rey, y Naung, 2012).

Joaquín Sorolla nació en Valencia en 1863. Recibió formación académica en la Escuela de Bellas Artes (1878-1881) y empezó a pintar al aire libre animado por uno de sus profesores, Gonzalo Salvá, y después, por el pintor Ignacio Pinazo Camarlench. En 1885 viaja a Roma y desde allí a París, donde entra en contacto con el naturalismo. De regreso a Roma, comienza a viajar por distintas ciudades italianas, tomando pequeñas notas de color. En 1887 se instala en Asís y allí empieza a hacer escenas de ambiente valenciano bajo la influencia de
José Benlliure y Gil. Es el inicio de su costumbrismo, que repercutirá en gran medida en su futura obra.

En 1889 vuelve a París para ver la Exposición Universal: allí descubre a los pintores nórdicos y su peculiar tratamiento de la luz, en el que él basará su propia versión del luminismo, abriéndose su etapa de consolidación. $\mathrm{Su}$ paleta va cobrando nuevos matices en su esfuerzo por plasmar la luz. Surgen nuevas temáticas, como el costumbrismo marinero, y el realismo social. Con el primero conseguirá su primer éxito internacional con "La vuelta de la pesca" en 1895, con el segundo diversos reconocimientos $(1892,1895$ y 190) y una Medalla de Honor.

A partir de 1900 se inicia su etapa de culminación, la del Sorolla más brillante, cuyas grandes dotes perceptivas y veloz ejecución, dan lugar a sus mejores obras, y donde la luz es el interés dominante de su trabajo. Sus constantes desplazamientos a París le hacen conocer las distintas vanguardias. Surgen así, los "ismos" en su pintura, siempre a modo de experimentación en su búsqueda por captar la luz. Hace retratos que le generan grandes ingresos, y se interesa por el paisaje. Sigue cultivando su costumbrismo marinero, del que derivan desde 1904 sus temas de playa, lo más reconocido de su producción, e inicia a partir de 1907 sus estudios de jardines, fundamentalmente en Andalucía.

En 1920 sufre un ataque de hemiplejía y poco a poco va languideciendo hasta el $10 \mathrm{de}$ agosto de 1923, fecha en que fallece en Cercedilla (Madrid).

En 1914 pinta este cuadro, "Joaquina la Gitana”, precisamente en su época más brillante, en la que la luz es el elemento más destacable de su obra y durante el que se producen sus mejores trabajos. 
En él, se puede observar a una mujer gitana que ocupa el centro de la escena, cuyo rostro aparece entre luz y sombras, sobre un fondo malva-gris y que destaca por su oscura vestimenta. Está sentada en un banco de color amaderado, apoyada sobre el respaldo y un poco inclinada hacia la derecha. Entre sus brazos y de forma relajada, sujeta a un niño. La mujer de edad indeterminada, ni muy joven, ni muy vieja, cuyos ojos se ocultan tras las sombras, parece mirar más allá del cuadro, con una expresión pensativa. Sus labios cerrados pero no apretados, dejan vislumbrar una tenue sonrisa. De aspecto humilde pero aseado, viste ropa oscura que no deja adivinar su silueta. Falda y sobrefalda hasta los pies, cuerpo de manga larga hasta un poco más arriba de las muñecas, sobre el que parece llevar un chal también oscuro, con una pequeña abertura en forma de pico que deja entrever un poco del escote. De pelo, piel y cejas oscuras, luce una flor en tonos amarillos sobre la oreja izquierda, prendida en lo que se adivina un recogido poco elaborado. Entre su brazos y con las manos entrelazadas, sujeta a un bebé, cuya cabecita está vuelta hacia su seno izquierdo, dando a entender que está mamando de él, mientras la manita izquierda del niño descansa sobre el pecho de ella.

El bebé, de abundante pelo castaño, vestido con una camisita blanca moteada con algún lunar oscuro, de manga larga, y cuyas piernecitas parecen estar cubiertas con la sobrefalda de la mujer, resalta sobre la ropa oscura de la gitana. La escena está iluminada por una luz lateral desde la derecha, que la divide en dos partes bien diferenciadas y que desvía nuestra atención hacia esta zona. La parte izquierda está sumida en la sombra, mientras que la parte derecha es mostrada con mucha más amabilidad, y llena de luz.
Encontramos así dos personalidades de la misma mujer. En la parte izquierda, se nos presenta a una mujer vestida de negro, una mujer arraigada a las tradiciones. Es la "mujer de respeto" que cumple con las normas del pueblo gitano, rico en expresiones simbólicas que dan cuenta de la riqueza que entraña, y que nos sorprende con las manifestaciones de duelo (luto) que debe persistir tras la muerte de un familiar(Moreno y Sánchez-Oro 2006), En la otra mitad y en otro estilo bien distinto, aparece reflejado el aspecto maternal de la gitana, retratada con mucha luz a pesar de vestir de negro y ser una figura muy oscura, con su hijo en brazos al que parece estar dando el pecho. La lactancia materna está condicionada por factores psicológicos, biológicos, culturales, sociodemográficos, económicos, y genéticos. Desde siempre se ha pensado que las madres gitanas prolongan la lactancia materna durante más tiempo que las madres no gitanas (De Amici, Gasparoni, Chirico, Bgliolo, 1998), además de dar el pecho en cualquier lugar y circunstancia, por lo que se trata de una escena que no sorprende al espectador. No por ello deja de ser una escena que contrasta con la otra mitad ya que en contraposición a la tristeza, el luto, el respeto silencioso, se muestra el lado más femenino de la mujer gitana, que se esfuerza por no expresar públicamente la alegría y el placer contenidos en su sonrisa. Es la feliz madre transmisora de valores y tradiciones que cuida y disfruta de sus hijos, esposa que cumple con lo que de ella se espera, pero sin perder su lado sensual y coqueto, que está representado por la flor amarilla que adorna su pelo oscuro. El amarillo, color brillante y alegre y que se asocia con la expresión de nuestros pensamientos, contrasta en este caso, con la austeridad e impersonalidad de la vestimenta de la protagonista. 


\section{CONCLUSIONES}

A través del análisis de la obra de Joaquín Sorolla, Joaquina la gitana, hemos podido acercarnos un poco más a la realidad de la mujer gitana, y comprender sus vivencias, dentro del entorno cultural del pueblo gitano.

Hablar de mujer gitana, es hablar del cuidado de los hijos, el mantenimiento de la casa, la transmisión de la cultura, la obediencia, la madre, la esposa, la hija, la virginidad... (Moreno, Sánchez-Oro, 2006). Y es que a pesar de los cambios que en la actualidad se están produciendo en cuanto a formación y acceso al mercado laboral de las mujeres gitanas, todavía siguen ligadas y se sienten completamente identificadas con su cultura y sus valores (Montañés, 2011).

Aunque el papel de la mujer gitana dentro de su entorno, pueda ser considerado como secundario, ya que se encuentra enmarcado en una comunidad claramente patriarcal, ella tiene el papel protagonista en el cuidado y mantenimiento de la familia, asumiendo de forma respetuosa lo que el grupo espera de ella, pero sin perder sus atributos femeninos. Sin embargo, y cada vez con más fuerza las mujeres gitanas están asumiendo nuevos retos en el ámbito público y laboral, lo que nos hace pensar que a pesar de su resignación y obligaciones sociales, es más fuerte la luz que la ilumina como madre y mujer, que intenta abrirse camino en un mundo en el que no es necesario renunciar a la identidad social, para ser una mujer de nuestro tiempo (Aguilar, 2007).

\section{BIBLIOGRAFÍA}

- Aguilar, C. (2007) Género, Interculturalidad y Percepción de la Identidad Gitana a través de la lij. X Simposio Internacional. Lengua, literatura y género. Baeza.

- Amezcua, M. (2012) Cómo realizar un estudio iconográfico en historia de los cuidados. II Encuentro Internacional de Historia y pensamiento enfermero. Casa Má- gina. Disponible en http://www.slideshare.net/f-index/ ii-encuentro-internacional-de-historia-y-pensamiento-enfermero. (Consultado 20-04-2013)

- De Amici, D; Gasparoni, A; Chirico, G; Bogliolo, O. (1998) The influence of race on breast feeding. European Journal of epidemiology 14: 413-415. Disponible en http://link.springer.com/article/10.1023/ A\%3A1007410518912. (Consultado 03- 04- 2014)

- Medina, E; Sánchez, Y; Rey, W; Naung, Y. (2012) La identidad cultural en la obra de arte. Aproximaciones a su estudio, en Contribuciones a las Ciencias Sociales. Disponible enwww.eumed.net/rev/cccss/20/. (Consultado 07-06-2014)

- Montañés, P. (2011) Una aproximación a la realidad de las mujeres gitanas desde la perspectiva de género. Acciones e Investigaciones Sociales 29: 87104. Disponible en http://dialnet.unirioja.es/servlet/ articulo? codigo=3734191. (Consultado 05-06-2014)

- Moreno, J; Sánchez-Oro, M. (2006). Un estudio cualitativo de la minoría gitana. la vigencia de los componentes de la estructura social. Documentación social 14: 143-158. Disponible en http://sociologiaext.wordpress. com/2007/05/16/un-estudio-cualitativo-de-la-minoria-gitana-vigencia-de-los-componentes-de-la-estructura-social/. (Consultado 05-06-2014)

- Panofsky, E. (1955) Iconography and iconology: an introduction to the study of renaissance art. In Meaning in the Visual Arts: Papers in and on Art History. Garden City, Doubleday NY: 26-54.

- Rodríguez, M.I. (2005) Introducción a los estudios iconográficos y a su metodología. E-excellence. www.liceus. com. (Consultado 05-05-2014) 